\title{
Técnica de fixação de tubos nasogástrico e nasoentérico
}

\section{Fastening technique of nasogastric and nasoenteric tubes}

Andy Petroianu - TCBC-MG'; Jac Petroianu²

R E S U M O

\begin{abstract}
Cateteres nasogástrico e nasoenteral são necessários na prática médica, porém são desagradáveis e dificilmente tolerados por longos períodos. Este trabalho descreve uma técnica de fixação do cateter nasogástrico ou nasoenteral de fácil execução e que reduz o desconforto, evitando as complicações provocadas por seu posicionamento inadequado. Após passar uma solução de benjoim sobre o cateter e a pele, uma fita adesiva, medindo 13 centímetros de comprimento por um centímetro de largura, envolve completamente o tubo e é, em seguida, fixada sobre o lábio superior. Essa fixação centraliza o cateter dentro da narina. O tubo para nutrição enteral é curvado para cima e fixado, com outra fita adesiva, ao dorso do nariz. Por último, com uma terceira fita adesiva, o cateter é aderido à testa. Os tubos mais largos, para descompressão gástrica, devem ser fixados inicialmente sobre o lábio superior e, em seguida, à região deltopeitoral. A fixação do cateter nasogástrico ou nasoentérico com fita adesiva sobre o lábio superior, com reforço sobre nariz e testa ou região deltopeitoral é simples, fácil e com custo mínimo, podendo ser realizada em qualquer ambiente, acompanhada de pouco incômodo para o paciente.
\end{abstract}

Descritores: Tubo nasogástrico. Tubo nasoentérico. Técnica de fixação. Complicações.

\section{INTRODUÇÃO}

$A$ tubagem nasogástrica tem por finalidade, identificar, drenar e quantificar o conteúdo gástrico, determinar o pH do estômago, manter o pertuito esofágico e nutrir o paciente. Esta última função também é exercida pelo tubo nasoentérico. Portanto, esses dispositivos são muito úteis na prática médica, com destaque para a Cirurgia Geral e do Sistema Digestório.

Com o avanço dos conhecimentos médicos, a descompressão gástrica pós-operatória em procedimentos abdominais saiu da rotina cirúrgica. Esse dispositivo é aplicado somente em situações especiais, quando ocorre dilatação do estômago, íleo prolongado ou desconforto, por plenitude epigástrica. Em contrapartida, a nutrição por via de cateter nasoenteral aumentou muito a sua indicação, sendo quase obrigatória em operações de maior porte, quando o paciente não pode ser nutrido por via oral. Dessa forma, se e por um lado, utilizam-se menos os tubos nasogástricos, por outro lado, os nasoenterais passaram a ser muito mais freqüentes.

\section{TÉCNICA}

Esta experiência iniciou em 1979 e consiste em fixar-se o cateter nasogástrico com uma fita adesiva microporosa ou de esparadrapo sobre o lábio superior. Inicialmente, passa-se uma gaze umedecida com benjoim em torno do cateter, sobre o lábio, dorso do nariz e testa ou região deltopeitoral. Após a secagem dessa solução, uma fita adesiva, medindo 13 centímetros de comprimento por um centímetro de largura, envolve completamente o tubo e é, em seguida, fixada sobre o lábio superior. (Figura 1). Em pacientes com bigode, coloca-se outra fita adesiva invertida tampando a parte adesiva da primeira fita na extensão do bigode e aderem-se as extremidades da primeira fita, que é mais comprida, ao rosto.

Quando o cateter tem por finalidade a nutrição enteral, ele é curvado para cima e fixado com outra fita adesiva, enrolada inicialmente em torno do cateter, ao dorso do nariz. Por último, com uma terceira fita adesiva, o cateter é preso à testa. (Figura 2). Esse dobrar do cateter para ser atado à testa previne o incômodo do paciente e reduz o

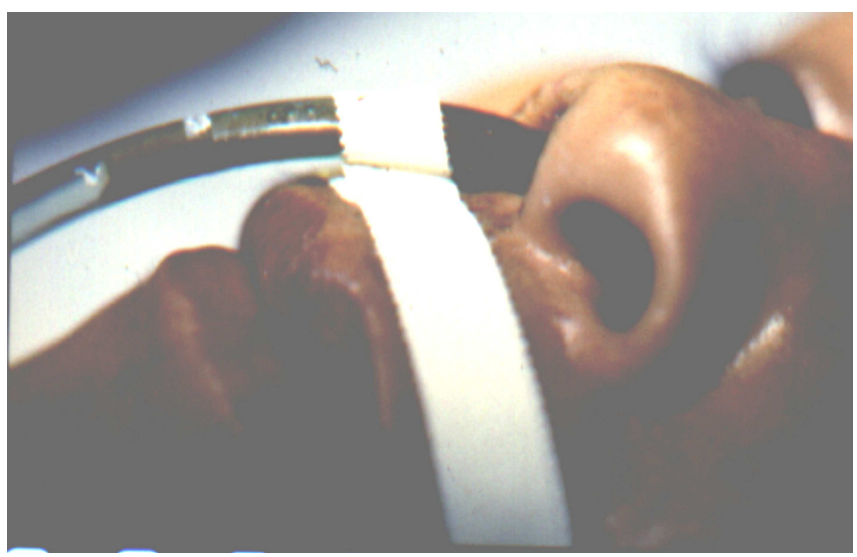

Figura 1 - Fixação de cateter. Cateter nasogástrico para drenagem do estômago. Observar a centralização do cateter na narina, sem tocar em suas paredes.

Trabalho realizado na Serviço de Cirurgia Geral da Santa Casa de Belo Horizonte MG-BR.

1. Professor Titular do Departamento de Cirurgia da Faculdade de Medicina, UFMG- MG-BR. 2. Pesquisador Titular. 
risco de tração acidental, com sua conseqüente saída ou ferimento nasal.

Os tubos para descompressão gástrica, que são mais calibrosos, devem ser fixados inicialmente sobre o lábio superior e, em seguida, à região deltopeitoral. Essa segunda fixação tem por objetivo não puxar o lábio e evitar que uma tração acidental machuque o paciente.

Esse tipo de fixação mantém o tubo centralizado e imobilizado na narina, sem tocar nas paredes nasais, independentemente de qualquer movimento da cabeça ou manipulação do tubo.

Na literatura e na prática médica existe um grande número de fixações do cateter nasogástrico ou nasoenteral, com a utilização de fios, barbantes e até pontos passados na pele do lábio superior ou da asa do nariz, aliados ao uso de esparadrapo ou fitas adesivas microporosas. A fixação do cateter nasogástrico ou nasoenteral com fita adesiva sobre o lábio superior e reforço sobre dorso do nariz e testa ou região deltopeitoral é simples, de fácil execução e com custo mínimo, podendo ser realizada em qualquer ambiente, acompanhada de menor incômodo para o paciente.

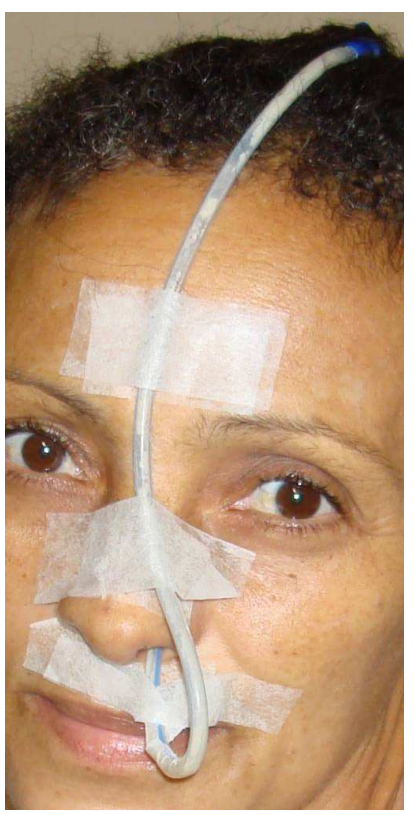

Figura 2 - Fixação de cateter. Cateter nasoenteral, para nutrição enteral. Observar a fixação ao lábio, ao dorso do nariz e à testa.

\title{
A B S T R A C T
}

\begin{abstract}
Nasogastric and nasoenteral tubes are necessary in medical practice, but they are unpleasant and hard to be tolerated during long periods. This paper describes a technique of fastening the nasogastric or nasoenteral catheter that is easy to be performed, diminishes the discomfort and avoids most of nasal complications related to its location. Benjoim solution moistens the tube and the skin of the upper lip, nose, forehead or deltopeitoral region. A micropore adhesive tape measuring 13 centimeters length and one centimeter width surrounds the tube and fastens it to the upper lip. This fastening centralizes the catheter into the nasal hole. The nasoenteral catheter is fastening on the upper lip, and then it is turned up, to be attached to nose and forehead with two other adhesive tapes. The larger nasogastric tube, used for gastric drainage, is fastened to the upper lip and attached on the deltopeitoral region with another adhesive tape. The nasogastric or nasoenteral tube fastening technique on the upper lip is easy, efficacious, inexpensive and can be performed in any environment with less discomfort of the patient.
\end{abstract}

Key words: Nasogastric tube. Nasoenteric tube. Fastening technique. Complications.

Recebido em 02/03/2009

Aceito para publicação em 14/05/2009

Conflito de interesse: nenhum

Fonte de financiamento: nenhuma

\section{Como citar esse artigo:}

Petroianu A, Petroianu J. Técnica de fixação de tubos nasogástrico e nasoentérico. Rev Col Bras Cir. [periódico na Internet] 2010; 37(1).

Disponível em URL: http://www.scielo.br/rcbc

Endereço para correspondência:

Prof. Andy Petroianu

E-mail: petroian@gmail.com 